\section{Risk factors associated with optic disc haemorrhage in patients with normal tension glaucoma}

Y-d Kim ${ }^{1,2}$, SB Han², KH Park², SH Kim², SJ Kim²,3, M Seong ${ }^{2,4}$, TW Kim² and DM Kim²

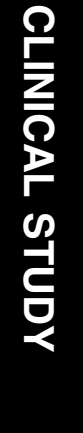

${ }^{1}$ Glaucoma and Cataract Services, HanGil Eye Hospital, Incheon, Republic of Korea

${ }^{2}$ Department of Ophthalmology, Seoul National University College of Medicine, Seoul, Republic of Korea

${ }^{3}$ Department of Ophthalmology, Konyang University, Kim's Eye Hospital, Seoul, Republic of Korea

\section{Introduction}

In normal tension glaucoma (NTG), optic disc haemorrhage is known to be a significant negative prognostic factor. ${ }^{1}$ The haemorrhage typically shows a flame- or splinter-like shape at the border of the optic disc. ${ }^{2,3}$ In early glaucoma, haemorrhage is usually located in inferotemporal or superotemporal optic disc regions. Localized wedge-shaped defects of the retinal nerve fibre layer (RNFL) are significantly associated with optic disc haemorrhage in both NTG and primary open angle glaucoma (POAG) patients. ${ }^{4}$ It is not clear, however, whether RNFL defects result from or cause optic disc haemorrhages. Neuroretinal rim notches and corresponding field losses are also associated with RNFL defects. $^{2,5-7}$ Optic disc haemorrhage is rare in normal eyes and is a strong diagnostic clue for the presence of glaucomatous optic disc damage, even if the visual field is normal. ${ }^{8,9}$

Some studies have suggested associations between optic disc haemorrhage and certain risk factors, ${ }^{8,10,11}$ but most studies included few or no NTG cases. As it is considered that optic disc condition is one of the most important prognostic factors for NTG, we sought to identify risk factors associated with optic disc
${ }^{4}$ Department of Ophthalmology, Hanyang University College of Medicine, Seoul, Republic of Korea

Correspondence: KH Park, Department of Ophthalmology, Seoul National University College of Medicine, 28 Yongondong, Chongno-gu, Seoul 110-744, Republic of Korea Tel: + 8222072 3172; Fax: + 8227413187

E-mail: kihopark@ snu.ac.kr

Received: 10 November 2008

Accepted in revised form: 2 May 2009 Published online: 24 July 2009

This article was presented at The Korean Glaucoma Society Annual Meeting, 24 November 2007, Seoul, Korea 
haemorrhage in NTG patients. A recent study reported that the prevalence of NTG (in $92 \%$ of POAG patients) in far-east Asia is much higher than elsewhere. ${ }^{12}$ Thus, identification of disc haemorrhage risk factors is particularly important in Korea.

The purpose of this study was thus to evaluate haemorrhage risk factors in NTG patients by examination of systemic, ophthalmic, social, and habitual factors.

\section{Materials and methods}

This study adhered to the tenets of the Declaration of Helsinki and was approved by our Institutional Review Board. From 2 February 2007 to 31 August 2007, NTG patients were enrolled to complete the prospective study questionnaire after giving informed consent. All patients were diagnosed with NTG at the Glaucoma Clinic, Seoul National University Hospital, and were followed up for at least 1 year. Study questionnaires were completed in clinic, by telephone, and by mail. Medical records were retrospectively reviewed. Inclusion criteria were

(1) intraocular pressure (IOP) lower than $21 \mathrm{~mm} \mathrm{Hg}$ by Goldmann applanation tonometry, without medication;

(2) glaucomatous optic disc change, such as notching or thinning of the neuroretinal rim, an acquired pit in the optic nerve, and/or an RNFL defect; (3) a correlated visual field defect, with mean deviation (MD) better than $-15 \mathrm{~dB}$, as measured by the central 30-2 program of the Humphrey Field Analyzer (Carl Zeiss Meditec Inc., Dublin, CA, USA); and (4) a normal open angle by gonioscopy. Exclusion criteria were (1) concomitant ocular disease that might lead to non-glaucomatous optic disc haemorrhage, (2) high myopia (more than six diopters), (3) severe cataract(s) that might affect visual field MD, (4) severe visual field defect(s) with MD worse than $-15 \mathrm{~dB}$, and (5) suspicion of glaucoma, such as large disc cupping without obvious RNFL or visual field defects. We enrolled patients with diabetes and hypertension who did not have severe diabetic or hypertensive retinopathy. Patients were divided into a haemorrhage group, in which optic disc haemorrhage had occurred at least once during the follow-up period, and a non-haemorrhage group. A disc haemorrhage was defined as an isolated flame-shaped or splinter-like haemorrhage on the optic disc or peripapillary area extending to the border of the optic disc. Recurrent haemorrhage was defined as enlargement of an earlier disc haemorrhage or a new disc haemorrhage that arose elsewhere. Only one eye was randomly chosen if a patient had disc haemorrhages in both the eyes in the haemorrhage group, or NTG in both the eyes in the nonhaemorrhage group.
Two hundred and eighty-one patients (281 eyes) with NTG were enrolled; 113 eyes with disc haemorrhage and 168 eyes without haemorrhage. Questionnaire items were patient-related variables: presence of diabetes, systemic hypertension, hypotension, cardiac disease, stroke, cold hand, migraine, constipation, smoking history, glaucoma family history, earlier ocular surgery, earlier ocular trauma, and use of steroid, aspirin, anticoagulant, or gingko extract. Reviewed eye-related variables were baseline IOP, maximum and minimum IOPs, IOP range (the difference between maximum and minimum IOP), vertical and horizontal cup/disc ratios, MD and pattern standard deviation of the visual field, central corneal thickness, and average RNFL thickness as measured by Stratus optical coherence tomography (Carl Zeiss Meditec). Patient- and eye-related data taken at the earlier time closest to the first haemorrhage were used, except for IOP data. Baseline IOP was measured before commencement of glaucoma medication. Maximum and minimum IOPs were measured at regular follow-up periods, and data from the follow-up session before the first haemorrhage were taken. In patients who had experienced earlier refractive surgery, measured IOPs were corrected to reflect altered central corneal thicknesses. No patient among earlier ocular trauma cases showed angle recession.

Logistic regression analysis was used to identify risk factors for optic disc haemorrhage. Logistic regression analysis (only) was used to determine factors related to frequency of haemorrhage. Each variable was initially evaluated by univariate analysis and significant variables

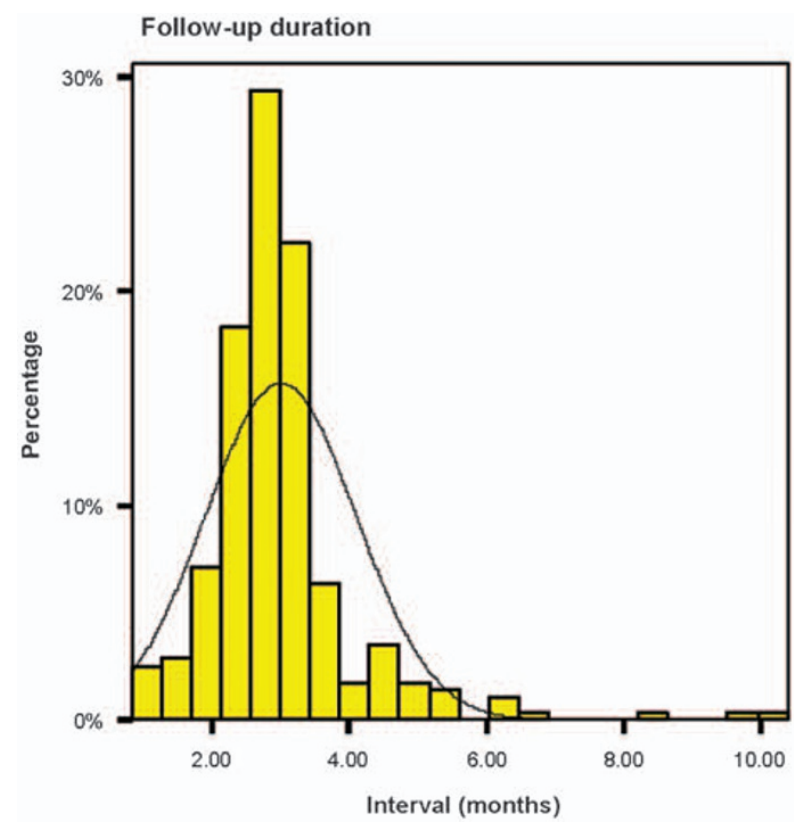

Figure 1 Patient follow-up duration. The mean follow-up interval for all patients was $2.9 \pm 1.1$ months (range 1-10 months) and most patients visited our clinic every $2-4$ months. 
$(P<0.1)$ were included in multivariate regression. The statistical analyses were performed with SPSS software, version 12.0 (SPSS Inc., Chicago, IL, USA).

\section{Results}

The mean patient age was $59.1 \pm 11.6$ years and mean follow-up time was $6.4 \pm 2.5$ years. The mean follow-up interval for all patients was $2.9 \pm 1.1$ months (range 1-10

Table 1 Demographic and baseline data of 281 patients with normal tension glaucoma

\begin{tabular}{lc}
\hline Age (years) $^{\mathrm{a}}$ (range) & $59.1 \pm 11.6(19-85)$ \\
Gender $^{\mathrm{a}}$ & $\mathrm{M}=126, \mathrm{~F}=155$ \\
Follow-up period (years) $^{\mathrm{a}}$ (range) & $6.4 \pm 2.5(1-11.8)$ \\
Log MAR visual acuity $^{\mathrm{a}}$ & $0.12 \pm 0.31$ \\
Baseline IOP (mm Hg) $^{\mathrm{a}}$ & $15.23 \pm 2.82$ \\
VF MD (dB) $^{\mathrm{a}}$ & $-4.44 \pm 4.11$ \\
VF PSD (dB) $^{\mathrm{a}}$ & $5.86 \pm 4.29$
\end{tabular}

$\mathrm{IOP}$, intraocular pressure; $\mathrm{MD}$, mean deviation; $\mathrm{PSD}$, pattern standard deviation; VF, visual field.

${ }^{\mathrm{a}}$ Mean \pm standard deviation. months), and most patients visited our clinic every $2-4$ months (Figure 1). Disc examinations were performed directly, or by disc photography, whenever patients visited our clinic. Demographic and baseline data are shown in Table 1. In the optic disc haemorrhage group, 87 patients had single haemorrhages and 26 recurrent haemorrhages. By logistic univariate regression analysis, more patients with optic disc haemorrhages had systemic hypertension than did patients without haemorrhages; the difference was statistically significant $(P=0.001)$. IOP range $(P=0.080)$, diabetes $(P=0.056)$, and use of aspirin $(P=0.079)$ tended to be associated with disc haemorrhage (all $P$-values were below 0.1 ), but did not reach statistical significance (Table 2). Logistic multivariate regression analysis using selected variables showed that only systemic hypertension was significantly associated with optic disc haemorrhage, with an odds ratio of 1.998 (95\% confidence interval 1.094-3.651) (Table 3).

There was no factor significantly associated with logistic univariate regression analysis between the single

Table 2 Univariate logistic regression analysis of systemic and ocular variables

\begin{tabular}{|c|c|c|c|}
\hline & Optic disc haemorrhage group $(\mathrm{n}=113)$ & Control group $(\mathrm{n}=168)$ & P-value \\
\hline Age (years) ${ }^{\mathrm{a}}$ & $59.9 \pm 11.7$ & $58.5 \pm 11.5$ & 0.296 \\
\hline Gender $^{\mathrm{a}}$ & $\mathrm{M}=47, \mathrm{~F}=66$ & $\mathrm{M}=79, \mathrm{~F}=89$ & 0.370 \\
\hline Baseline IOP $(\mathrm{mm} \mathrm{Hg})^{\mathrm{a}}$ & $15.33 \pm 2.47$ & $15.17 \pm 3.06$ & 0.651 \\
\hline IOP range $(\mathrm{mm} \mathrm{Hg})^{\mathrm{a}}$ & $5.15 \pm 2.43$ & $4.60 \pm 2.58$ & 0.080 \\
\hline Maximum IOP $(\mathrm{mm} \mathrm{Hg})^{a}$ & $16.19 \pm 3.17$ & $15.65 \pm 3.20$ & 0.169 \\
\hline Minimum IOP $\left(\mathrm{mm} \mathrm{Hg}^{\mathrm{a}}\right.$ & $11.04 \pm 2.12$ & $11.05 \pm 2.10$ & 0.970 \\
\hline Vertical cup/disc ratio ${ }^{\text {a }}$ & $0.73 \pm 0.14$ & $0.72 \pm 0.16$ & 0.484 \\
\hline Horizontal cup/disc ratio ${ }^{a}$ & $0.68 \pm 0.14$ & $0.69 \pm 0.37$ & 0.850 \\
\hline $\operatorname{VF} \operatorname{MD}(\mathrm{dB})^{\mathrm{a}}$ & $-4.20 \pm 4.18$ & $-4.58 \pm 4.08$ & 0.486 \\
\hline VF PSD $(\mathrm{dB})^{\mathrm{a}}$ & $5.71 \pm 4.52$ & $5.95 \pm 4.16$ & 0.671 \\
\hline Corneal thickness $(\mu \mathrm{m})^{\mathrm{a}}$ & $516.13 \pm 31.64$ & $515.11 \pm 30.50$ & 0.827 \\
\hline OCT: average thickness $(\mu \mathrm{m})^{\mathrm{a}}$ & $90.49 \pm 13.17$ & $87.56 \pm 15.44$ & 0.144 \\
\hline Glaucoma family history $^{\mathrm{b}}$ & $9 / 113(8 \%)$ & $15 / 166(9 \%)$ & 0.844 \\
\hline Cardiac disease $\mathrm{b}^{\mathrm{b}}$ & $8 / 92(9 \%)$ & $11 / 166(7 \%)$ & 0.237 \\
\hline Stroke ${ }^{\mathrm{b}}$ & $9 / 113(8 \%)$ & $14 / 168(8 \%)$ & 0.912 \\
\hline Hypertension $^{\mathrm{b}}$ & $43 / 113(38 \%)$ & $42 / 168(25 \%)$ & 0.001 \\
\hline Hypotension $^{\mathrm{b}}$ & $5 / 107(5 \%)$ & $7 / 168(4 \%)$ & 0.841 \\
\hline Diabetes $^{\mathrm{b}}$ & $18 / 113(16 \%)$ & $20 / 168(12 \%)$ & 0.056 \\
\hline Constipation $^{\mathrm{b}}$ & $13 / 106(12 \%)$ & $21 / 167(13 \%)$ & 0.879 \\
\hline Cataract operation $^{\mathrm{b}}$ & $4 / 89(4 \%)$ & $13 / 167(8 \%)$ & 0.320 \\
\hline Glaucoma operation $^{b}$ & $0 / 89(0 \%)$ & 0/167 (0\%) & 0.277 \\
\hline Retinal operation $^{\mathrm{b}}$ & $1 / 89(1 \%)$ & $2 / 167(1 \%)$ & 0.958 \\
\hline Refractive operation $^{\mathrm{b}}$ & $3 / 89(3 \%)$ & $4 / 167(2 \%)$ & 0.650 \\
\hline Other ocular operation ${ }^{\mathrm{b}}$ & $2 / 89(2 \%)$ & $5 / 167(3 \%)$ & 0.728 \\
\hline Steroid use $\mathrm{e}^{\mathrm{b}}$ & $4 / 90(4 \%)$ & $4 / 162(2 \%)$ & 0.398 \\
\hline Aspirin $u^{b} e^{b}$ & $20 / 90(22 \%)$ & $27 / 165(16 \%)$ & 0.079 \\
\hline Anticoagulant use $\mathrm{e}^{\mathrm{b}}$ & $6 / 90(7 \%)$ & $8 / 161(5 \%)$ & 0.372 \\
\hline Gingko extract use $\mathrm{e}^{\mathrm{b}}$ & $9 / 90(10 \%)$ & $13 / 163(8 \%)$ & 0.408 \\
\hline Ocular trauma ${ }^{\mathrm{b}}$ & $3 / 84(4 \%)$ & $11 / 161(7 \%)$ & 0.791 \\
\hline Cold hand ${ }^{\mathrm{b}}$ & $31 / 108(29 \%)$ & $44 / 156(28 \%)$ & 0.566 \\
\hline Migraine $^{b}$ & $21 / 106(20 \%)$ & $49 / 151(32 \%)$ & 0.170 \\
\hline
\end{tabular}

IOP, intraocular pressure; MD, mean deviation; OCT, optical coherence tomography; PSD, pattern standard deviation; VF, visual field.

${ }^{a}$ Mean \pm standard deviation.

${ }^{b}$ Positive answers/total answers (\%). 
optic disc haemorrhage group and the recurrent haemorrhage group (Table 4).

\section{Discussion}

In the earlier studies, the prevalence of optic disc haemorrhage in NTG patients varied from 11 to $42 \% .^{3,13-16}$ The aetiology of optic disc haemorrhage is

Table 3 Multivariate logistic regression analysis of systemic and ocular variables

\begin{tabular}{lcccc}
\hline Risk factor & P-value & Odds ratio & \multicolumn{2}{c}{ 95\% Confidence interval } \\
\hline IOP range & 0.383 & 1.050 & 0.941 & 1.173 \\
Hypertension & 0.024 & 1.998 & 1.094 & 3.651 \\
Diabetes & 0.171 & 1.701 & 0.796 & 3.638 \\
Aspirin use & 0.712 & 1.145 & 0.558 & 2.348 \\
\hline
\end{tabular}

IOP, intraocular pressure.

Variables with $P<0.1$ on univariate logistic analysis were included in a multivariate regression. still unclear, but many studies have shown that glaucoma is associated with haemorrhage.

Rim notching, RNFL defects, and visual field deterioration are suspected to be associated with optic disc haemorrhage. ${ }^{2,17-22}$ Several studies have attempted to discover factors associated with disc haemorrhage in glaucoma patients and have suggested hypertension, ${ }^{2,8}$ diabetes, ${ }^{2,8,11}$ increasing IOP, pseudoexfoliation, ${ }^{8}$ and use of aspirin, ${ }^{11}$ as significant. In this study, we propose a relationship between systemic hypertension and optic disc haemorrhage. The IOP range, presence of diabetes, and use of aspirin were also implied as probable risk factors by univariate logistic regression analysis, but not on multivariate regression. Healey et $a l^{8}$ reported that diabetes, hypertension, higher IOP, and higher systolic blood pressure were associated with open angle glaucoma and, especially, that higher IOP, diabetes, and hypertension were strongly associated with NTG. Soares et $a l^{11}$ also showed that diabetes and use of aspirin were

Table 4 Univariate logistic regression analysis of systemic and ocular variables between the single haemorrhage group and the group with recurrent haemorrhagic events

\begin{tabular}{|c|c|c|c|}
\hline & Single haemorrhage group $(\mathrm{n}=87)$ & Recurrent haemorrhage group $(\mathrm{n}=26)$ & P-value \\
\hline Age (years) ${ }^{\mathrm{a}}$ & $59.78 \pm 12.30$ & $60.6 \pm 9.65$ & 0.760 \\
\hline Gender $^{\mathrm{a}}$ & $\mathrm{M}=35, \mathrm{~F}=52$ & $\mathrm{M}=12, \mathrm{~F}=14$ & 0.591 \\
\hline Baseline IOP $(\mathrm{mm} \mathrm{Hg})^{\mathrm{a}}$ & $15.27 \pm 2.32$ & $15.52 \pm 2.91$ & 0.650 \\
\hline IOP range $(\mathrm{mm} \mathrm{Hg})^{\mathrm{a}}$ & $3.91 \pm 3.15$ & $5.50 \pm 2.25$ & 0.432 \\
\hline Maximum IOP $(\mathrm{mm} \mathrm{Hg})^{\mathrm{a}}$ & $16.1 \pm 3.37$ & $16.28 \pm 2.48$ & 0.850 \\
\hline Minimum IOP $(\mathrm{mm} \mathrm{Hg})^{\mathrm{a}}$ & $11.16 \pm 2.34$ & $10.81 \pm 1.70$ & 0.531 \\
\hline Vertical cup/disc ratio ${ }^{\text {a }}$ & $0.73 \pm 0.14$ & $0.75 \pm 0.13$ & 0.411 \\
\hline Horizontal cup/disc ratio ${ }^{a}$ & $0.67 \pm 0.14$ & $0.72 \pm 0.13$ & 0.109 \\
\hline $\operatorname{VF} M D(d B)^{a}$ & $-4.27 \pm 4.19$ & $-3.95 \pm 4.22$ & 0.752 \\
\hline VF PSD $(d B)^{a}$ & $5.80 \pm 4.19$ & $5.45 \pm 4.22$ & 0.749 \\
\hline Corneal thickness $(\mu \mathrm{m})^{\mathrm{a}}$ & $512.98 \pm 32.60$ & $519.36 \pm 24.66$ & 0.442 \\
\hline OCT: average thickness $(\mu \mathrm{m})^{\mathrm{a}}$ & $89.88 \pm 12.80$ & $92.50 \pm 14.49$ & 0.434 \\
\hline Glaucoma family history $^{\mathrm{b}}$ & $8 / 113(8 \%)$ & $2 / 26(8 \%)$ & 0.690 \\
\hline Cardiac disease $\mathrm{b}^{\mathrm{b}}$ & $8 / 92(9 \%)$ & $1 / 21(5 \%)$ & 0.326 \\
\hline Stroke $\mathrm{e}^{\mathrm{b}}$ & $9 / 113(8 \%)$ & $4 / 26(15 \%)$ & 0.125 \\
\hline Hypertension $^{\mathrm{b}}$ & $43 / 113(38 \%)$ & $14 / 26(54 \%)$ & 0.222 \\
\hline Hypotension $^{\mathrm{b}}$ & $4 / 86(5 \%)$ & $1 / 21(5 \%)$ & 0.983 \\
\hline Diabetes $^{\mathrm{b}}$ & $18 / 113(16 \%)$ & $5 / 26(19 \%)$ & 0.871 \\
\hline Constipation $^{\mathrm{b}}$ & $13 / 106(12 \%)$ & $2 / 20(10 \%)$ & 0.640 \\
\hline Cataract operation ${ }^{\mathrm{b}}$ & $3 / 71(4 \%)$ & $1 / 18(6 \%)$ & 0.159 \\
\hline Glaucoma operation $^{\mathrm{b}}$ & $0 / 71(0 \%)$ & $0 / 18(0 \%)$ & 0.999 \\
\hline Retinal operation ${ }^{\mathrm{b}}$ & $1 / 71(1 \%)$ & $0 / 18(0 \%)$ & 1.000 \\
\hline Refractive operation $^{\mathrm{b}}$ & $3 / 71(4 \%)$ & $0 / 18(0 \%)$ & 0.999 \\
\hline Other ocular operation ${ }^{\mathrm{b}}$ & $1 / 71(1 \%)$ & $1 / 18(6 \%)$ & 0.326 \\
\hline Steroid use $\mathrm{e}^{\mathrm{b}}$ & $4 / 71(6 \%)$ & $0 / 19(0 \%)$ & 0.999 \\
\hline Aspirin use $\mathrm{e}^{\mathrm{b}}$ & $15 / 71(21 \%)$ & $5 / 19(26 \%)$ & 0.932 \\
\hline Anticoagulant use $\mathrm{b}^{\mathrm{b}}$ & $5 / 71(7 \%)$ & $1 / 19(5 \%)$ & 0.648 \\
\hline Gingko extract use $\mathrm{b}^{\mathrm{b}}$ & $6 / 71(8 \%)$ & $3 / 19(16 \%)$ & 0.469 \\
\hline Ocular trauma ${ }^{\mathrm{b}}$ & $2 / 67(3 \%)$ & $1 / 17(6 \%)$ & 0.955 \\
\hline Cold hand ${ }^{\mathrm{b}}$ & $24 / 84(29 \%)$ & $7 / 24(29)$ & 0.903 \\
\hline Migraine $^{\mathrm{b}}$ & $16 / 83(19 \%)$ & $5 / 23(22 \%)$ & 0.932 \\
\hline
\end{tabular}

IOP, intraocular pressure; $\mathrm{MD}$, mean deviation; OCT, optical coherence tomography; PSD, pattern standard deviation; VF, visual field.

${ }^{a}$ Mean \pm standard deviation.

${ }^{\mathrm{b}}$ Positive answers/total answers (\%). 
risk factors in patients with POAG. Optic disc haemorrhage can be caused not only by ischemic microinfarction in the optic disc, but also by mechanical rupture of small blood vessels arising from structural changes at the level of the lamina cribrosa. ${ }^{2,23,24}$ As vasculopathy associated with systemic hypertension and diabetes can cause microinfarctions and ischemic changes in optic disc vessels, making these vessels vulnerable to mechanical rupture, ${ }^{25}$ it is logical that such microvascular diseases are correlated with optic disc haemorrhage in NTG patients.

Any association between optic disc haemorrhage and systemic hypertension is still controversial. Several earlier studies reported an effect of systemic hypertension on optic disc haemorrhage, ${ }^{8,26}$ but other reports could not confirm such a link..$^{11,27,28}$ In one of our earlier studies we suggested the probability of a common vascular pathophysiology shared by branch retinal vein obstruction (BRVO) cases and NTG patients with optic disc haemorrhage. ${ }^{29}$ In that work, we showed a $50 \%$ incidence of disc haemorrhage in patients with both NTG and BRVO, which was higher than seen in earlier studies; most of our patients had systemic hypertension. Moreover, the pathogenesis of NTG is thought to be associated with vascular ischemia in the optic nerve head rather than mechanical disruption of the nerve head caused by high IOP. ${ }^{30}$ These results lead us to suggest that some NTG subgroups show higher frequencies of disc haemorrhage than do patients with other types of glaucoma, and, in this study, we show that hypertension is a strong risk factor for optic disc haemorrhage in NTG patients.

We also found that aspirin use tended to be associated with optic disc haemorrhage. Aspirin prevents thromboxane A2 production, which, in turn, promotes platelet aggregation by inhibition of cyclo-oxygenase. Therefore, aspirin use can increase the risk of optic disc haemorrhage and also the time needed to absorb the haemorrhage. These factors increase the probability that optic disc haemorrhage will be detected during followup. Another possible explanation is that patients using aspirin are more likely to have vascular diseases that can further the development of optic disc haemorrhage; in our study, however, earlier cardiac disease and stroke history were not associated with optic disc haemorrhage.

Some investigators have reported that hypotension, especially nocturnal arterial hypotension, may lead, through ocular hypoperfusion, to progression of NTG. ${ }^{31-33}$ In this study, however, no relationship between hypotension and optic disc haemorrhage was found. We found no differences in risk factors between the single optic disc haemorrhage group and the recurrent haemorrhage group.

Kitazawa et $a l^{34}$ reported that optic disc haemorrhages usually persisted for 2-35 weeks, with an average of 10.6 weeks. Most of our patients were followed up at 2-4 month intervals, but we cannot exclude the possibility that we may have missed some haemorrhages that occurred between follow-up appointments.

In conclusion, our study showed that NTG patients with systemic hypertension were at higher risk for development of optic disc haemorrhages. Patients with diabetes and those using aspirin might also be at higher risk. These findings suggest that systemic hypertension, diabetes, and use of aspirin may be associated with deterioration of NTG. A further study is required to explore the pathological details of optic disc haemorrhages and the pathophysiological association between hypertension and such haemorrhages.

\section{Acknowledgements}

The authors have no proprietary interest or financial support in the development or marketing of instruments or equipment mentioned in this article, or any competing instruments or equipment.

\section{References}

1 Ishida K, Yamamoto T, Sugiyama K, Kitazawa Y. Disk hemorrhage is a significantly negative prognostic factor in normal-tension glaucoma. Am J Ophthalmol 2000; 129: 707-714.

2 Drance SM. Disc hemorrhages in the glaucomas. Surv Ophthalmol 1989; 33: 331-337.

3 Kitazawa Y, Shirato S, Yamamoto T. Optic disc hemorrhage in low-tension glaucoma. Ophthalmology 1986; 93: 853-857.

4 Sugiyama K, Uchida H, Tomita G, Sato Y, Iwase A, Kitazawa Y. Localized wedge-shaped defects of retinal nerve fiber layer and disc hemorrhage in glaucoma. Ophthalmology 1999; 106: 1762-1767.

5 Airaksinen PJ, Mustonen E, Alanko HI. Optic disc hemorrhages. An analysis of stereophotographs and clinical data of 112 patients. Arch Ophthalmol 1981; 99: 1795-1801.

6 Heijl A. Frequent disc photography and computerized perimetry in eyes with optic disc hemorrhage. Acta Ophthalmol 1986; 64: 274-281.

7 Sugiyama K, Tomita G, Kitazawa Y, Onda E, Shinohara H, Park KH. The associations of optic disc hemorrhage with retinal nerve fiber layer defect and peripapillary atrophy in normal-tension glaucoma. Ophthalmology 1997; 104: 1926-1933.

8 Healey PR, Mitchell P, Smith W, Wang JJ. Optic disc hemorrhages in a population with and without signs of glaucoma. Ophthalmology 1998; 105: 216-223.

9 Bengtsson B. Optic disc hemorrhages preceding manifest glaucoma. Acta Ophthalmol 1990; 68: 450-454.

10 Budenz DL, Anderson DR, Feuer WJ, Beiser JA, Schiffman J, Parrish II RK et al. Detection and prognostic significance of optic disc hemorrhages during the Ocular Hypertension Treatment Study. Ophthalmology 2006; 113: 2137-2143.

11 Soares AS, Artes PH, Andreou P, Leblanc RP, Chauhan BC, Nicolela MT. Factors associated with optic disc hemorrhages in glaucoma. Ophthalmology 2004; 111: 1653-1657. 
12 Iwase A, Suzuki Y, Araie M, Yamamoto T, Abe H, Shirato S et al. The prevalence of primary open-angle glaucoma in Japanese: the Tajimi Study. Ophthalmology 2004; 111: 16411648.

13 Drance SM, Sweeney VP, Morgan RW, Feldman F. Studies of factors involved in the production of low-tension glaucoma. Arch Ophthalmol 1973; 89: 457-465.

14 Shirato S, Koseki N. Disc hemorrhage in low-tension glaucoma. In: Krieglstein GK (ed). Glaucoma Update IV. Springer-Verlag: Berlin, 1991; 125-128.

15 Levene RZ. Low tension glaucoma: a critical review and new material. Surv Ophthalmol 1980; 24: 621-664.

16 Chumbley LC, Brubaker RF. Low-tension glaucoma. Am J Ophthalmol 1976; 81: 761-767.

17 Bengtsson B. Findings associated with glaucomatous visual field defects. Acta Ophthalmol 1980; 58: 20-32.

18 Shihab ZM, Lee P, Hay P. The significance of disc hemorrhage in open-angle glaucoma. Ophthalmology 1982; 89: $211-213$

19 Drance SM. Hemorrhage on disc - a risk factor in glaucoma. In: Krieglstein GK, Leydhecker W (eds). Glaucoma Update II. Springer-Verlag: Berlin, 1983; 77-79.

20 Siegner SW, Netland PA. Optic disc hemorrhages and progression of glaucoma. Ophthalmology 1996; 103: 1014-1024.

21 Ishida K, Yamamoto T, Kitazawa Y. Clinical factors associated with the progression of normal-tension glaucoma. J Glaucoma 1998; 7: 372-377.

22 Rasker MT, Enden A, Bakker DB, Hoyng PF. Deterioration of visual fields in patients with glaucoma with and without optic disc hemorrhages. Arch Ophthalmol 1997; 115: 12571263.

23 Drance SM, Begg IS. Sector hemorrhage - a probable acute ischaemic disc change in chronic simple glaucoma. Can J Ophthalmol 1970; 5: 137-141.
24 Quigley HA, Addicks EM, Green WR, Maumenee AE. Optic nerve damage in human glaucoma. II. The site of injury and susceptibility to damage. Arch Ophthalmol 1981; 99: 635-649.

25 Cooper ME, Bonnet F, Oldfield M, Jandeleit-Dahm K. Mechanisms of diabetic vasculopathy: an overview. Am J Hypertens 2001; 14: 475-486.

26 Drance SM, Fairclough M, Butler DM, Kottler MS. The importance of disc hemorrhage in the prognosis of chronic open angle glaucoma. Arch Ophthalmol 1977; 95: 226-228.

27 Diehl DL, Quigley HA, Miller NR, Sommer A, Burney EN. Prevalence and significance of optic disc hemorrhage in a longitudinal study of glaucoma. Arch Ophthalmol 1990; 108: 545-550.

28 Grodum K, Heijl A, Bengtsson B. Optic disc hemorrhages and generalized vascular disease. J Glaucoma 2002; 11: 226-230.

29 Yoo YC, Park KH. Disc hemorrhages in patients with both normal tension glaucoma and branch retinal vein occlusion in different eyes. Korean J Ophthalmol 2007; 21: 222-227.

30 Flammer J, Orgül S, Costa VP, Orzalesi N, Krieglstein GK, Serra LM et al. The impact of ocular blood flow in glaucoma. Prog Retin Eye Res 2002; 21: 359-393.

31 Graham SL, Drance SM, Wijsman K, Douglas GR, Mikelberg FS. Ambulatory blood pressure monitoring in glaucoma. The nocturnal dip. Ophthalmology 1995; 102: 61-69.

32 Graham SL, Drance SM. Nocturnal hypotension: role in glaucoma progression. Surv Ophthalmol 1999; 43(suppl): 10-16.

33 Hayreh SS. The role of age and cardiovascular disease in glaucomatous optic neuropathy. Surv Ophthalmol 1999; 43(suppl): 27-42.

34 Kitazawa Y, Shirato S, Yamamoto T. Optic disc hemorrhage in low-tension glaucoma. Ophthalmology 1986; 93: 855-857. 